\title{
Corrigendum: Misty, Spellbound and the lost Gothic of British girls' comics
}

Julia Round

Correction to: Palgrave Communications (2017) 3 Article number: 17037 doi:10.1057/palcomms.2017.37; Published 16 May 2017; Updated 3 Oct 2017

On page 6 of the PDF, in the second paragraph beginning "I also surveyed Misty's entire run of stories", the sentence "However it does give a sense of the weighting given to named Gothic archetypes in Misty content-and reveals that they make up just $22 \%$ of its total content" has been corrected to "However it does give a sense of the weighting given to named Gothic archetypes in Misty-and reveals that these make up just $25 \%$ of its total comic strip content."

In Table 1 on page 6 , the data for "The Devil" has been corrected as follows:

\section{Table 1 | Gothic archetypes in Misty}

\begin{tabular}{llcc} 
Archetype & Appearances & Total & \% (of 606 comics stories) \\
\hline Ghosts & 22 one-shots, 5 serials (49 episodes) [+21 prose] & 71 & 11.72 \\
The Devil & 5 one-shots, 1 serial (17 episodes) & 22 & 3.63 \\
Witches & 21 one-shots & 21 & 3.47 \\
Vampires & 9 one-shots, 1 serial (12 episodes) [+2 prose] & 21 & 7 \\
Zombies & 1 one-shot, 1 serial (6 episodes) & 6 & 3.47 \\
Werewolves & 6 one-shots & 3 & 0.99 \\
Skeletons & 3 one-shots & 2 & 0.5 \\
Frankenstein's creature & 2 one-shots & 2 & 0.33 \\
Warlocks & 2 one-shots & $\mathbf{1 5 5}$ & 0.33 \\
TOTAL & & $\mathbf{2 5 . 5 8}$ \\
\hline
\end{tabular}

The article has been corrected online. 